\title{
Moving on in life after intensive care - partners' experience of group communication
}

\author{
Mona Ahlberg, Carl Bäckman, Christina Jones, Sten Walther and Gunilla Hollman Frisman
}

\section{Linköping University Post Print}

\section{Tweet}

N.B.: When citing this work, cite the original article.

Original Publication:

Mona Ahlberg, Carl Bäckman, Christina Jones, Sten Walther and Gunilla Hollman Frisman, Moving on in life after intensive care - partners' experience of group communication, 2015, Nursing in Critical Care, (20), 5, 256-263.

http://dx.doi.org/10.1111/nicc.12192

Copyright: Wiley: 12 months

http://eu.wiley.com/WileyCDA/

Postprint available at: Linköping University Electronic Press

http://urn.kb.se/resolve?urn=urn:nbn:se:liu:diva-119295 
Moving on in life after intensive care - partner's experience of group-communication

Ahlberg $\mathrm{M}^{1}$, Bäckman $\mathrm{C}^{2}$, Jones $\mathrm{C}^{3}$, Walther $\mathrm{S} \mathrm{M}^{4}$, Hollman Frisman $\mathrm{G}^{5}$.

${ }^{1}$ Department of Anesthesiology and Intensive Care, Nurse, Vrinnevi Hospital, 60182 Norrköping, Sweden.

2 Department of Anesthesiology and Intensive Care, Vrinnevi Hospital, 60182 Norrköping, Sweden.

${ }^{3}$ Musculoskeletal Biology, Institute of Ageing \& Chronic Disease, University of Liverpool, Liverpool, UK

${ }^{4}$ Department of Thoracic and Vascular Surgery, and Department of Medical and Health Sciences, Linköping University, 58185 Linköping, Sweden.

${ }^{5}$ Anesthetics, Operations and Speciality Surgery Center and Department of Medical and Health Sciences, Division of Nursing Sciences. Linköping University, 58185 Linköping, Sweden.

Corresponding author: Mona Ahlberg, Department of Anesthesiology and Intensive Care, Vrinnevi Hospital, 60182 Norrköping, Sweden, E-mail;

mona.k.ahlberg@ regionostergotland.se Phone +46101042337. 


\begin{abstract}
Background

Partners have a burdensome time during and after their respectives' time on intensive care. Outwardly they may appear to be coping well but inside feel vulnerable and lost. Studies evaluating interventions for partners are limited.
\end{abstract}

Aim

The aim of this study was to describe the experience of those participating in groupcommunication with other partners of former intensive care patients.

Design

The study has a descriptive intervention, based design where group-communication for partners of surviving ICU-patients, was evaluated.

Methods

A strategic selection was made of adult partners to former adult intensive care patients $(n=15)$ five men and ten women, 37-89 years. Two group-communication sessions lasting two hours were held one month apart with three to five partners of former intensive care patients. The partners afterwards described their feelings about participating in group-communication, in a notebook. To deepen the understanding, six of the partners were interviewed. Content analysis was used to analyze the notebooks and the interviews.

Findings

Three categories were identified: 1) Emotional impact, the partners felt togetherness and experienced worry and gratitude, 2) Confirmation, being conscious of their situation through insight and reflection, 3) Session design, group constellation and willingness to recommend participate in group-communication. 


\section{Conclusion}

Partners of an intensive care patient constantly have to adapt to new situations and find new strategies to cope. Group-communication contributed to a feeling of togetherness and confirmation. To share experiences with others is one way for partners to be able to move on in life.

Relevance to clinical practice

Group-communication with other partners eases the burden of being a partner to a former intensive care patient. Group-communication needs to be further developed and evaluated, so as to obtain consensus and evidence for best practice.

\section{Keywords}

Communication, content analysis, intensive care, nursing, partners. 


\section{Background}

Experience of a life-threatening illness or injury, requiring intensive care (ICU) affects the individual and their partner dramatically during and after the period of illness (Bäckman, et al., 2010; Jones, et al., 2010; Jones, et al., 2012; Davidson, et al., 2012; Prinjha, et al., 2009) . Health-related quality, of, life has been shown to be significantly lower among patients after an ICU stay compared to the population at large (Bäckman, et al., 2010). The stay on an ICU also decreases the patient's partner's health-related quality, of, life (Davidson, et al., 2012; Ågren, et al., 2012) wich is why it is important to give partners confidence and the opportunity to rest, both physically and psychologically, to conserve their inner strength, as they are also important for the patients' recovery (Ågren, et al., 2009; Bergbom and Askwall, 2000; Basińska, et al., 2011).

Partners have a burdensome time during the patients' stay on the ICU, and must learn to adapt to a constantly changing situation. They may appear to be coping well outwardly but inside have a sense of being vulnerable and lost. The ICU-nurse has an important supporting role offering empathy, providing information and explaining the ICUcare being given so that the partner understands and feels comfortable with the patients' care (Heyland, et al., 2002; Nelms and Eggenberger, 2010; Lee and Lau, 2003). Exchange of information and effective communication with the entire ICU staff, especially the physician, increases the partners' confidence in the ICU care given to the patient (Azoulay, et al., 2000; Jacobwski, et al., 2010; Johnson, et al., 1998). Furthermore, plans for future care should be presented to the partner in a way they understand, this is of great importance for the partner (Engström and Söderberg, 2004).

During the patient's stay on the ICU, the partner often alternates between hope and despair related to managing the life situation (Bäckman, et al., 2010; Jones, et al., 2010; 
Jones, et al., 2012; Davidson, et al., 2012). The partner often worries about the future, as patients treated in ICU for weeks are sometimes unable to return to their physical level they had before the severe illness or injury. Critical illness thus become a crucial stage for the partner also (Jones, et al., 2012).

It is therefore important that the ICU-nurse offers the partner support, honest information and attention giving the feeling that they are important and noticed, helping the partner to adapt to the situation (Wåhlin, et al., 2009). If the partner is given the opportunity to be involved in the care of the patient, the relationship with the nurses will be improved and the partners' participation in the caring team will be alleviated to the patient (Wåhlin, et al., 2009; Garrouste-Orgeas, et al., 2010).

Despite, many studies reporting that partners to ICU patients's suffer psychologically, there only are a few studies examining interventions aiming to ease the partner's life-situation. In this study were partners offered participation in groupcommunication sessions, with subsequent evaluation of how the group-communication was experienced.

\section{Aim}

The aim of this study was to describe the partners' experience of participation in groupcommunication with other partners of former intensive care patients.

\section{Design}

The study has a descriptive intervention, based design where group-communication between partners of former, surviving ICU-patients, is evaluated. 


\section{Methods}

All participants had visited the ICU follow-up clinic together with their partner, ICU patient.

Participants

A strategic selection of adult participants (>18 years), partners of former ICU patients, was made. The inclusion criteria were: To be a partner of an intensive care patient who had had an ICU stay of at least 96 hours, in the previous six to 18 months, the partner should have visited the ICU follow-up clinic on at least one occasion after the ICU stay. The partner should be able to attend two meetings, and to communicate in verbal and written Swedish. Partners of former ICU patients were contacted on the telephone and mail and were asked to participate in the study. They were given information about the aim of the study, confidentiality, the voluntary nature of the study and that they could withdraw at any time. Partners who agreed to participate $(n=15)$, five men and ten women, gave written informed consent by mail (Figure 1).

Intervention

Three to five partners of former ICU patients participated in two group communication sessions lasting two hours and one month apart. An experienced ICU nurse (MA), who is also involved in the ICU follow-up clinic, led the group-communication sessions and made sure everyone was given the opportunity to speak during the meeting. The ICU nurse began by explaining the study's purpose, that participation was voluntary, and that all data would be treated confidentially. 
At the first group session the participants were guided by the ICU nurse to talk about what happened before and during their partner's ICU stay, and what their thoughts were about this period. After this the participants were encouraged to speak freely. The second group session was held one month after the first and focused on the partner's thoughts and experiences after the patient had been discharged from the ICU, to the ward, and then further to their home, until the day of the group-communication session. Approximately 15 minutes before the end of the session a summary of what had been achieved was made.

Data collection

After each group session the participants were asked to write about their feelings on group-communication in a notebook they were given after the first session. The participants were asked to write freely about their experience of group-communications, and they also were asked to provide their age, gender, and education / occupation. The notebook contained information about the study and the partners were also asked to answer the following questions:

- Do you feel that you have been affected in some way? If so, how? Why?

- Has group-communication dragged up any feelings? Which? Why?

- Did today's group-communication give you anything? In which case, what?

After the second group-communication, four additional questions were posed;

- Was the group-communication session too soon after the ICU stay?

- What do you think about the number of participants in the group?

- If the possibility existed would you like to continue the group-communication? 
- Would you recommend this type of group-communication to others? Please explain why?

After the second meeting the partners received a franked addressed envelope and were asked to return their notebooks by mail. The written content of the notebooks were copied and returned to those partners who wished to have them back.

As the contents of the notebooks were sparse, individual interviews were performed to deepen our understanding of participation in group-communication. All those who participated in the group-communication sessions were asked to be interviewed, of those two men and four women gave informed consent. Five of the interviews were conducted at the hospital in a room next to the ICU, and one in the partners' home. The same question's that were asked in the notebook were used in the interview. The interviews were recorded on tape and transcribed verbatim by the first author (MA) performing the interviews. The interviews lasted 12 to 38 minutes.

Analysis

Content analysis was used to analyze the contents of the notebooks and the transcribed interviews. Participants' notebooks and the transcribed interviews were read several times by the first and the last authors (MA, GHF). So as to familiarize to themselves with the data, sentences and phrases containing information relevant to the purpose of the study were individually identified as "meaningful units". Similar meaningful units were given the same code. The codes were thereafter sorted into categories and subcategories. The authors discussed the analyses to find similarities and differences until consensus was reached. The meaningful units, categories and subcategories were read over and over again to determine each meaningful unit, category and subcategory. The analysis steps were processed 
back and forth to validate codes previously identified. Genuine quotes have been used to increase the credibility of the findings (Krippendorff, 2004; Krippendorff, 2013).

To ensure trustworthiness a third session was organized after the first groupcommunications sessions', where the ICU nurse summed up what the partners had formulated in their notebooks. Participants verified what was written and summarized their thoughts as described in their notebooks.

Ethics considerations

The Regional Ethics Committee approved the study. In accordance with the Helsinki Declaration the partners were assured of confidentiality and the voluntary nature of their participation throughout the process. An amendment of the structure of the study was presented to the Regional Ethics Committee regarding deepening the study by personal interviews. All data from the notebooks and interviews were saved and stored according to current law.

\section{Findings}

The participating partners were 37-89 years (Md 66, $\left.\mathrm{Q}_{1} 57, \mathrm{Q}_{3} 73\right)$, nine were pensioners and six of the partners were working. Numbers of days between hospital stay and the groupcommunication ranged from 94 - 600 (Md 206, $\mathrm{Q}_{1}$ 149, $\left.\mathrm{Q}_{3} 398\right)$. The patients were admitted to the ICU because of a life, threatening illness, postoperative complication, or trauma and stayed in the ICU between five and 47 days.

The qualitative content analysis generated three categories and six subcategories

(Table 1). The three categories were: 1) Emotional impact 2) Confirmation 3) The session 
design. The quotes presented are expressions from the notebooks (letters) and the interviews (numbers).

Emotional impact

The partners were in favor of the study and looked forward to the groupcommunication session. They had had positive experiences from the ICU follow-up clinic, and the patients' ICU photo-diaries had given them and the patient support in their emotional recovery.

Togetherness

The partners felt they benefited from the group-communication through sharing experiences of and reflections over their respective's ICU-stay with other partners. They felt togetherness with the others in the group. Some expressed that not all participants spoke about their experiences of the ICU-stay, but all felt they could speak freely.

"I instantly felt togetherness with the others in the group, since we'd all experienced approximately the same" (G)

Group-communication confirmed their reflections and thoughts and even though they were strangers to each other from the beginning they found it easy to speak. They related the experience of togetherness to the fact that they had similar experiences and were in a similar situation. 
Experience of worries and gratitude

The partners declared that they had been nervous about being introduced to the others at the first group-communication. Despite this the conversation flowed well and everyone got the chance to talk. At the second group-communication the partners felt more at ease with each other, as though they knew each other. Some participants felt that the groupcommunication dragged up feelings they had repressed and forgotten. They had trouble falling asleep after the session, slept badly and dreamt a lot.

"When we told and discussed, our experiences many feelings arose that I had repressed, but it felt good to share my experiences with like-minded" (B)

At the second group-communication session some related that they had experienced the first session as being so traumatic that at first they felt they did not want to attending the next session, but came anyway and were pleased to be there, after the second session they felt better.

\section{Confirmation}

Meeting others, discussing feelings and be finding that their feelings were normal, gave a sense of confirmation.

\section{Consciousness}

The partners felt very alone with their thoughts. They expressed their experience of decreased psychological well-being but had suppressed their own emotions because they 
were not the person who was seriously ill and in need of support. They felt they had put their own life aside to be able to be there and help their loved one in any way they could. They experienced a sense of living in a vacuum. When the patient was discharged home, everything was expected to be normal again, making it difficult to be the responsible caregiver.

"You feel very alone in this situation, having your partner severely ill on the ICU "(2)

Existential thoughts that they might have lost their partner, came now and then, but the awareness of the value of life made it easier to depress anxious feelings that something serious might happen to their partner again.

"I feel grateful and the meaning of some things have changed for me" (A)

They were now feeling the strength to live a good life instead of worrying continuously.

Insight and reflection

The thought that it was meaningful to help others in need of emotional support was crucial to the partners. Some partners were more focused on the patients' upbringing and whole life story than the ICU stay. However, the partners gained insight through sharing their experiences of existential crises.

"It was mainly through one of the other participants that I was able to recognize myself and the situation I was in" $(K)$ 
The partners found it valuable to listen to and be involved in the others' stories as well as to share their own. The insights they gained during group-communication were both fearful and meaningful.

"I think it's important to reflect as we did in the group discussions, to be able to go on in life as a stronger individual (6)"

Through reflection it was possible to go on in life as a stronger individual in a new family situation. Reflection also helped when talking of feelings in the close family. The partner's role in their relationship changed during the ICU stay demanding adaption to a new life situation.

The session design

Even though the group-communication sessions occurred between 94 to 600 days after the patient's ICU stay only a few felt the interval to be too long. They felt they might have benefited more by having the sessions earlier; six months after discharge from the ICU would be optimal.

"Time-wise, I think the group communication sessions are well-timed, you've got some distance to the illness and rehabilitation has gone well” (F) 


\section{Group constellation}

The partners that answered the question on whether or not the group had the right number of participants all agreed that the group constellation of three to five participants was optimal.

"The number of participants was just right, I got the feeling that all participants had opportunity to speak" (1)

Most partners were positive about the group constellation although there was a mix of gender and ages. However, some expressed that they had nothing in common with connect the others, and felt they didn't contribute a thing. Those who were critical wanted more individual communication with the ICU nurse and/or other personal from the ICU, and talk in private rather than in a group.

After the second group-communication session the partners were more satisfied, saying it felt good to talk about what had happened and what could have been done differently. The session became more relaxed and the partners felt they knew each other better. On the other hand those who did not attend the second group-communication session explained that they were too occupied and didn't see any good in proceeding with groupcommunication.

\section{Recommendation}

Most partners would recommend group-communication to others, though they had some thoughts about how to improve the sessions. Some wanted further groupcommunication sessions but others thought it was enough. Some of the participants were clear 
that they would recommend this kind of group-communication to others, but they also made it clear that "it is not a walk in the park".

"I can recommend this to others because it provides additional perspective on how it is to suffer from a serious illness; how differently we are affected, and how different are the conditions one has to return" (F)

\section{Discussion}

As far as we are aware, this is the first study evaluating group-communication between the partners of surviving intensive care patients. The main finding of this study was that the participating partners, through conscious insight, reflection and confirmation benefited from group-communication with others with similar experiences.

The partners described themselves as "living in a vacuum", that hopefully may be released through reflection with other partners with similar experiences. Being conscious of putting one-self aside and gaining confirmation of one's feelings may ease the understanding of one's own feelings and reactions. Similar to the group-communication sessions in this study, drop-in meetings for former ICU-patients and their partners have been developed at a hospital in the UK (Peskett and Gibb, 2009). Information about the drop-in meetings were posted on noticeboards with a headline aimed to capture the attention of those who could relate to their purpose, "empathy, not sympathy". An ICU follow-up nurse opened the meeting, but thereafter remained quiet. She played an important role, however in looking after new visitors. Participants at these meetings gave positive feedback. They felt, like the participants in our study that they benefited from sharing their experiences with others even though no-one lead the conversation (Jones, 2013). 
Through sharing experiences of and reflections over the ICU-stay with other partners, a sense of togetherness with others was expressed, the partners found it meaningful to help others. No longer being alone with their thoughts and suppressed feelings, they now became aware of their decreased psychological well-being. The burden of being a partner to a critical ill patient can lead to increase in symptoms of anxiety and depression with time, which is why partners should be assessed for post-traumatic stress (PTSD) and complicated grief and offered help (McAdam, et al., 2010; Anderson, et al., 2008). Although many partners still have a high risk for developing PTSD, adequate follow-up up to three months after discharged of the patient and their partner from the intensive care unit has been shown to reduce the risk (McAdam, et al., 2012).

Sharing experiences with others dragged up feelings that the partners had repressed and forgotten, and they had trouble falling asleep after the group-communication session. However, they felt better after the second session when they once again met the others in the group and discussed their own emotions. Other studies have also reported that partners of ICU patients often suffer from insomnia, fatigue and anxiety (Elizarrarás-Rivas, et al., 2010; Day, et al., 2013). In order to better provide support and care for their respective when discharged, healthy partners must themselves have the opportunity to recover and to have a good night's sleep while the patient is still in hospital (McAdam and Puntillo, 2009). The ICU nurse needs to give the partner confidence to leave the hospital trusting that the patient gets the best care without their "watchful eye" (Carter and Clark, 2005). Moreover, experience of togetherness and not being alone achieved through group-communication may decrease worries and ease sleep at night.

Most partners were positive to the group sessions and would recommend others in similar situations to attend group-communication. The fact that group communication was experienced positively does not mean that the follow-up clinic and the patient's photo-diaries 
have less importance. What is written in the diary is of great significance, but personnel often find it difficult to write about emotions and difficult events and some needs encouragement to write (Perier, et al., 2013). Thus, ICU diaries and group-communication promote a healing process as part of the professional caring of the patient and their partner's well-being. Both diaries and the group-communication are a source of comfort and security for patients and their partners (Roulin, et al., 2007; Ewens, et al., 2014).

According to Jones (2013) suggests that having a structured pathway for patient rehabilitation is the first step towards better physical and psychological recovery. Early rehabilitation conducted by a multidisciplinary team along with the use of ICU dairies may reduce physical and mental health complications among partners also (Johansson, et al., 2005).

Few studies have examined what healthcare providers should do after discharge to protect the partner's health. Despite a growing literature on the partners' burden after critical illness, we still do not know what type of intervention produces the best improvement (Schmidt and Azoulay, 2012; Plost and Nelson, 2007; Engström, et al., 2008; Lautrette, et al., 2007).

Credibility was achieved through two of the authors (MA and GHF) first reviewing the data and reaching consensus about the analysis, and further credibility was ensured through two other authors (CB and SW) working as collaborating analysts during the data analysis (Lincoln \& Guba 1985). The data was read and confirmed by the fifth author (CJ). By using quotes, credibility and ability of the reader to interpret the findings are strengthened. The text in the notebooks written by the partners after each groupcommunication session was limited which is why the participants also were asked to be interviewed. Using two different sources of data could be seen as a limitation of this study. 
However, the interviews gave further information about the partners' experience of the groupcommunication sessions. Participants also verified the contents of their notebooks, so the use of these different data sources may be seen as strengthening.

\section{Clinical implications}

Group-communication with other partners in a similar situation helps them through the burden of being partner to a former ICU patient and during the recovery period. Groupcommunication sessions led by an experienced ICU-nurse should therefore be further developed, evaluated and implemented in ICU-units.

\section{Conclusion}

Partners to an intensive care patient are constantly having to adapt to new situations, finding new strategies to ever changing circumstances. Group-communications contributed to a feeling of togetherness and confirmation. Sharing experiences with others in similar situation is one way for partners to be able to move on in life.

\section{Acknowledgements}

We thank the partners for participating in the study. The study was supported by Anesthetics, Operations and Speciality Surgery Center, Region Östergötland and Department of Medical and Health Sciences, Division of Nursing Sciences. Linköping University, 58185 Linköping, Sweden. 


\section{What is known about this topic}

- Partners have a burdensome time during and after a partner's intensive care period.

- Partners appear to be coping well outwardly but inside feel vulnerable and lost.

- Interventions for these partners are limited evaluated.

\section{What this paper adds}

- Group-communications help partners to former intensive care patients to manage and find new strategies to an ever changing situation.

- To share experiences with others is one way for partners to be able to move forward in life.

\section{References}

Ågren S, Evangelista L, Davidson T, Strömberg A. (2012). The Influence of Chronic Heart Failure in Patient-Partner Dyads-A Comparative Study Addressing Issues of Health-Related Quality of Life. Journal of Cardiovascular Nursing; June 1

Ågren S, Hollman Frisman G, Berg S, Svedjeholm R, Strömberg A. (2009). Addressing spouses' unique needs after cardiac surgery when recovery is complicated by heart failure. Heart and Lung; 38:284-291

Anderson WG, Arnold RM, Angus DC, Bryce CL. (2008). Posttraumatic Stress and Complicated Grief in Family Members of Patients in the Intensive Care Unit. Journal of General Internal Medicine; 23(11):1871-1876 
Azoulay E, Chevret S, Leleu G, Pochard F, Barboteu M, Adrie C, Canoui P, Le Gall JR, Schlemmer B. (2000). Half the families of intensive care unit patients experience inadequate communication with physicians. Critical Care Medicine; 28(8):3044-3049

Basińska K, Owczuk R, Suchorzewska J, Wujtewicz M, Wujtewicz M. (2011). The relationship between family members of ntensive therapy unit patients and medical staff. Anaesthesiology Intensive Therapy; 43(2):74-78

Bergbom I, Askwall A. (2000). The nearest and dearest: a lifeline for ICU patients. Intensive and Critical Care Nursing; 16:384-395

Bäckman CG, Orwelius L, Sjöberg F, Fredrikson M, Walther SM. (2010). Long-term effect of the ICU-diary concept on quality of life after critical illness. Acta Anaesthesiologica Scandinavica; 54(3):736-743

Carter PA, Clark AP. (2005). Assessing and Treating Sleep Problems in Family Caregivers of Intensive Care Unit Patients. Critical Care Nurse; 25:16-23

Davidson JE, Jones C, Bienvenu OJ. (2012). Family response to critical illness:

Postintensive care syndrome-family. Critical Care Medicine; 40(2):618-624

Day A, Haj-Bakri S, Lubchansky S and Mehta S. (2013). Sleep, anxiety and fatigue in family members of patients admitted to the intensive care unit: a questionnaire study. Critical Care; 17:R91 
Elizarrarás-Rivas J, Vargas-Mendoza JE, Mayoral-Garcia M, Matadamas-Zarate C, Elizarrarás-Cruz A, Taylor M, Agho K. (2010). Psychological response of family members of patients hospitalised for influenza A/H1N1 in Oaxaca, Mexico. BioMed Central Psychiatry; 10(104):1-9

Engström A, Andersson S, Söderberg S. (2008). Re-visiting the ICU Experiences of followup visits to an ICU after discharge: a qualitative study. Intensive Critical Care Nursing; $24: 233-241$

Engström Å, Söderberg S. (2004 ). The experiences of partners of critically ill persons in an intensive care unit. Intensive and Critical Care Nursing; 20:299-308

Ewens B, Chapman R, Tulloch A, Hendricks JM. (2014). ICU survivors’ utilisation of diaries post discharge: A qualitative descriptive study. Australian Critical Care; 27:28-35

Garrouste-Orgeas M, Willems V, Timsit J-F, Diaw F, Brochon S, Vesin A, Philippart F, Tabah A, Coquet I, Bruel C, Moulard M-L, Carlet J, Misset B. (2010). Opinions of families, staff, and patients about family participation in care in intensive care units. Journal of Critical Care; 25:634-640

Heyland DK, Rocker GM, Dodek PM, Kutsogiannis DJ, Konopad E, Cook DJ, Peters S, Tranmer JE, O’Callaghan CJ. (2002). Family satisfaction with care in the intensive care unit: Results of a multiple center study. Critical Care Medicine; 30(7):1413-1418 
Jacobwski NL, Girard TD, Mulder JA, Ely WE. (2010). Communication in Critical Care:

Family Rounds in the Intensive Care Unit. American Journal of Critical Care; 19(5): 421-430

Johansson I, Fridlund B, Hildingh C. (2005). What is supportive when an adult next-of-kin is in critical care?. Nursing in Critical Care; 10(6):289-298

Johnson D, Wilson M, Cavanaugh B, Bryder C, Gudmundson D, Moodley O. (1998).

Measuring the ability to meet family needs in an intensive care unit. Critical Care Medicine; 26(2):266-271

Jones C. (2013). What's new on the post-ICU burden for patients and relatives?. Intensive Care Medicine; 39:1832-1835

Jones C, Bäckman C, Capuzzo M, Egerod I, Flaatten H, Granja C, Rylander C, Griffiths RD. (2010). Intensive care diaries reduce new onset post traumatic stress disorder following critical illness: a randomised, controlled trial. Critical Care; 14:R168

Jones C, Bäckman C, Griffiths RD. (2012). Intensive Care Diaries and Relatives’' Symptoms of Posttraumatic Stress Disorder After Critical Illness: A Pilot Study. American Journal of Critical Care; 21(3):172-176

Krippendorff K. (2013). Content Analysis An Introduction to Its Methodology, Third Edition. SAGE Publications Inc

Krippendorff K. (2004). Reliability in Content Analysis: Some Common Misconceptions 
and Recommendations. Human Communication Research 30; 3:411-433

Lautrette A, Darmon M, Megarbane B, Joly L M, Chevret S, Adrie C, Barnoud D, Bleicher G, Bruel C, Choukroun G, Curtis R, Fieux F, Galliot R, Garrouste-Orgeas M,Georges H, Goldgran-Toledano D, Jourdain M, Loubert G, Reignier J, Saidi F,Souweine B, Vincent F, Kentish Barnes N, Pochard F, Schlemmer B, Azoulay E. (2007). A communication strategy and brochure for relatives of patients dying in the ICU. The New England Journal of Medicine; 356:469-478

Lee LYK, Lau YL. (2003). Immediate needs of adult family members of adult intensive care patients in Hong Kong. Journal of Critical Nursing; 12:490-500

Lincoln YS, Guba EG. (1985). Naturalistic Inquiry. Newbury Park, CA; SAGE Publications McAdam JL, Dracup KA, White DB, Fontaine DK, Puntillo KA. (2010). Symtom experiences of family members of intensives care unit patients at high risk for dying. Critical Care Medicine; 38(4):1078-1085

McAdam JL, Fontaine DK, White DB, Dracup KA, Puntillo KA. (2012). Psychological symptoms of Family Members of High-Risk Intensive Care Unit Patients. American Journal of Critical Care; 21(6):386-394

McAdam JL, Puntillo K. (2009). Symptoms Experienced by Family Members of Patients in Intensive Care Units. American Journal of Critical Care; 18:200-210 
Nelms TP, Eggenberger SK. (2010).The Essence of the Family Critical IllnessExperience and Nurse-Family Meetings. Journal of Family Nursing; 16(4):462-486

Perier A, Revah-Levy A, Bruel C, Cousin N, Angeli S, Brochon S, Philippart F, Max A, Gregoire C, Misset B, Garrouste-Orgeas M. (2013). Phenomenologic analysis of healthcare worker perceptions of intensive care unit diaries. Critical Care; 17(13):1-7

Peskett M, Gibb P. (2009) Developing and setting up a patient and relatives intensive care support group. Nursing in Critical Care; 14(1):4-10

Plost G, Nelson D. (2007). Family care in the intensive care unit: the Golden Rule, evidence, and resources. Critical Care Medicine; 35:669-670

Prinjha S, Field K, Rowan K. (2009). What patients think about ICU follow-up services: a qualitative study. Critical Care; 13:R46

Roulin M-J, Hurst S, Spirig R. (2007). Diaries Written for ICU Patients. Qualitative Health Research; 17(7):893-901

Schmidt A, Azoulay E. (2012). Having a loved one in the ICU: the forgotten family. Current Opinion Critical Care; 18(5):540-547

Wåhlin I, Ek A-C, Idvall E. (2009). Empowerment in intensive care: Patient experiences compared to next kin and staff beliefs. Intensive and Critical Care Nursing; 25:332-340 
Wåhlin I, Ek A-C, Idvall E. (2009). Empowerment from the perspective of next of kin in intensive care. Journal of Clinical Nursing; 18:2580-2587 
Table 1. Categories and subcategories

\begin{tabular}{|l|l|l|}
\hline Emotional impact & Confirmation & The meeting design \\
\hline Togetherness & Consciousness & Group constellation \\
$\begin{array}{l}\text { Experience of worries and } \\
\text { gratitude }\end{array}$ & Insight and reflection & Recommendation \\
\hline
\end{tabular}




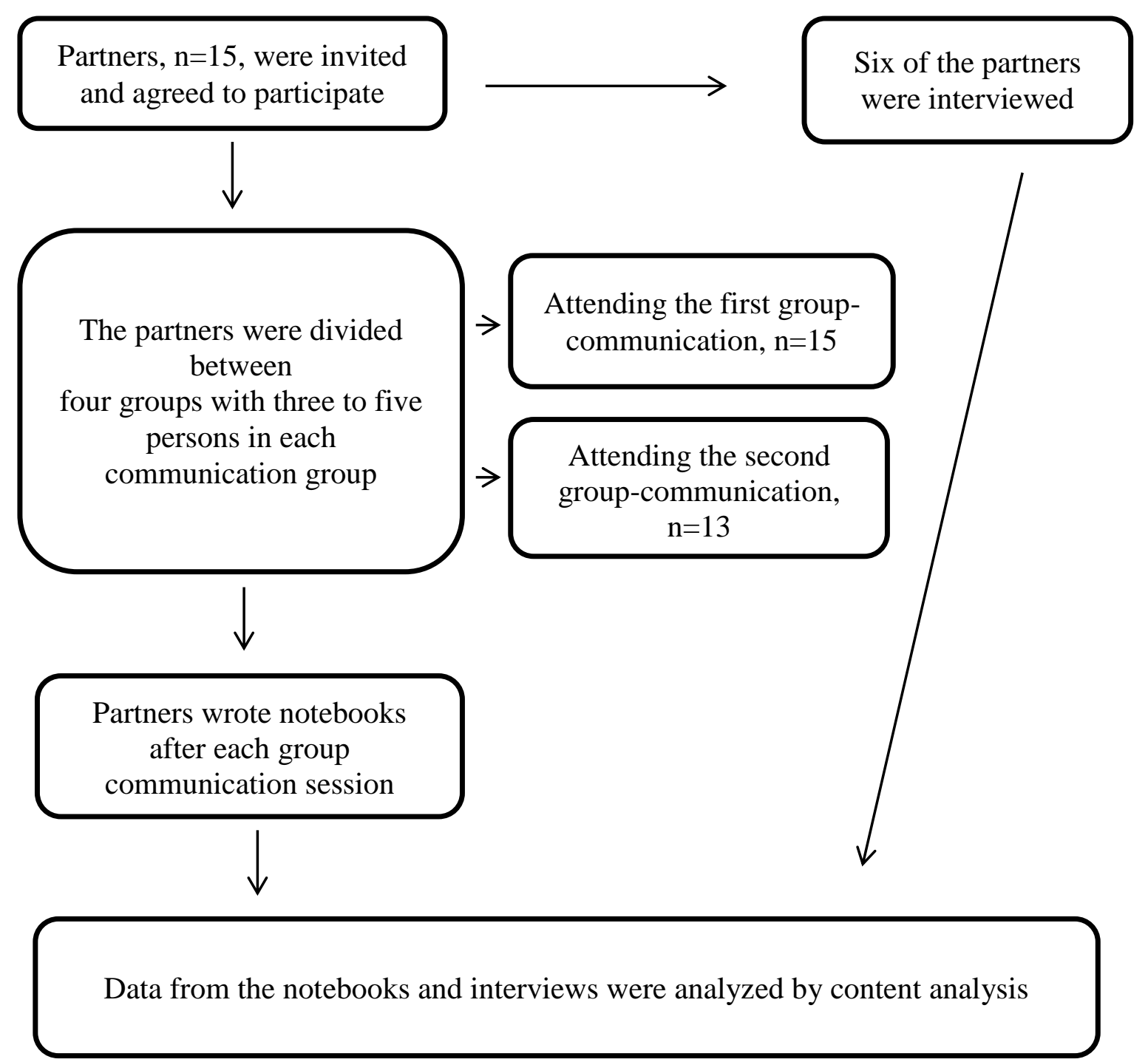

Figure 1. Out-line of the study 
